\title{
BMJ Open Supervision of care networks for frail community dwelling adults aged 75 years and older: protocol of a mixed methods study
}

\author{
Didi Verver, ${ }^{1}$ Hanneke Merten, ${ }^{1}$ Paul Robben, ${ }^{2,3}$ Cordula Wagner ${ }^{1,4}$
}

To cite: Verver D, Merten $\mathrm{H}$, Robben $\mathrm{P}$, et al. Supervision of care networks for frail community dwelling adults aged 75 years and older: protocol of a mixed methods study. BMJ Open 2015;5: e008632. doi:10.1136/ bmjopen-2015-008632

- Prepublication history for this paper is available online. To view these files please visit the journal online (http://dx.doi.org/10.1136/ bmjopen-2015-008632).

Received 29 April 2015 Revised 6 June 2015 Accepted 13 June 2015

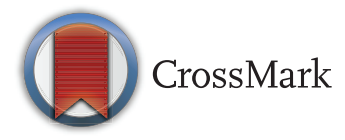

\footnotetext{
${ }^{1}$ Department of Public and Occupational health, EMGO + Institute/VU University Medical Centre, Amsterdam, The Netherlands

${ }^{2}$ Dutch Healthcare Inspectorate (IGZ), Utrecht, The Netherlands

${ }^{3}$ Institute of Health Policy and Management (BMG),

Erasmus Universiteit

Rotterdam, Rotterdam, The

Netherlands

${ }^{4}$ The Netherlands Institute for Health Services Research (NIVEL), Utrecht, The Netherlands
}

Correspondence to Didi Verver;

d.verver@vumc.nl

\section{ABSTRACT}

Introduction: The Dutch healthcare inspectorate (IGZ) supervises the quality and safety of healthcare in the Netherlands. Owing to the growing population of (community dwelling) older adults and changes in the Dutch healthcare system, the IGZ is exploring new methods to effectively supervise care networks that exist around frail older adults. The composition of these networks, where formal and informal care takes place, and the lack of guidelines and quality and risk indicators make supervision complicated in the current situation.

Methods and analysis: This study consists of four phases. The first phase identifies risks for community dwelling frail older adults in the existing literature. In the second phase, a qualitative pilot study will be conducted to assess the needs and wishes of the frail older adults concerning care and well-being, perception of risks, and the composition of their networks, collaboration and coordination between care providers involved in the network. In the third phase, questionnaires based on the results of phase II will be sent to a larger group of frail older adults $(n=200)$ and their care providers. The results will describe the composition of their care networks and prioritise risks concerning community dwelling older adults. Also, it will provide input for the development of a new supervision framework by the IGZ. During phase IV, a second questionnaire will be sent to the participants of phase III to establish changes of perception in risks and possible changes in the care networks. The framework will be tested by the IGZ in pilots, and the researchers will evaluate these pilots and provide feedback to the IGZ.

Ethics and dissemination: The study protocol was approved by the Scientific Committee of the EMGO +institute and the Medical Ethical review committee of the VU University Medical Centre. Results will be presented in scientific articles and reports and at meetings.

\section{INTRODUCTION}

Problem definition

The Dutch Healthcare Inspectorate (IGZ, Dutch acronym) promotes public health

\section{Strengths and limitations of this study}

- Since the study is embedded within the academic collaborative centre on supervision (AWT), there is a close collaboration with the Dutch healthcare inspectorate (IGZ) during all phases. They support and advise the researchers, this may facilitate implementation of the results in practice.

- This study is divided into four phases, using different methods. Every phase builds on information that is gathered in the previous phase. In this way, the most important and relevant aspects are being studied.

- Research concerning supervision is a growing field, but research concerning supervision on care networks is a fairly new area. This research will contribute to the knowledge in this area.

- This study examines a relevant issue for society because of the rising number of community dwelling older adults. The patients perspective is important in this study, owing to the increasingly importance of it in current policies.

- Results from this study could be biased by the so-called 'window dressing' of healthcare providers, as they are aware of the involvement of the IGZ and therefore they could give desired answers.

through effective enforcement of the quality of health services, prevention measures and medical products in the Netherlands. The IGZ collaborates with healthcare providers, insurers and representative groups of patients to produce appropriate indicator sets with which the IGZ can supervise. Healthcare providers are responsible for developing standards and guidelines which the IGZ can use in the supervision process. For a large group of frail community dwelling older adults, there are currently no (scientific) guidelines or quality and safety norms with which the IGZ is able to regulate; the group is heterogeneous and this 
hampers the development of such norms. Quality systems exist for care institutions and for professional care providers, but a quality system for care networks is lacking. ${ }^{1}$ Furthermore, it is unclear to what extent networks exist around community dwelling frail older adults and which risks are important to take into account. Current supervision frameworks, laws, field standards and guidelines offer too little for the IGZ to supervise care networks in the current situation. This becomes even more important with the changes in the Dutch healthcare system, where the independence and selfreliance of people is emphasised. ${ }^{2}$ Difficulties arising from these changes are discussed below.

\section{Care networks}

A network can be defined as a more or less stable pattern of social relations among different actors (people, groups, organisations) who depend on each other to reach their goals without the existence of a dominant actor. Network relations imply that coordination among actors takes place on the basis of mutual benefit, reciprocity and trust. ${ }^{3}{ }^{4}$ In this study, we speak of a care network when a combination of support, care, nursing or treatment by different professionals and informal care providers is present, more or less simultaneously and with clients who live independently. A formal collaboration is not necessarily present.

\section{Frail older adults}

The world population is ageing and the global share of older adults (aged 60 years or over) will rise from $11.7 \%$ in 2013 to $21.1 \%$ in $2050 .{ }^{5}$ The expansion of the population of older adults causes an increase in frail older adults. ${ }^{6}$ Frailty is a widely discussed subject in developed countries and many studies have been published on this topic. $^{7-11}$ Nevertheless, an internationally accepted definition of frailty is lacking. Definitions vary from broad to narrow, where physical frailty is most often discussed. $^{9-11}$ However, the term frailty can also describe health from a more integrated approach instead of a medical-based perspective. In this study, the definition of the Dutch Institute for Social Research (2011) (SCP, Dutch acronym) will be used. They describe frailty as follows: "A process of an accumulation of physical, psychological and/or social deficits in functioning which increases the chance of adverse health outcomes (functional disabilities, admission to an institution, death)". ${ }^{10}$

Frail older adults often have needs which require the efforts of multiple healthcare professionals and organisations. ${ }^{12} 13$ According to the report of the SCP, in 2011 approximately 690000 frail older adults live in the Netherlands, which accounts for $27 \%$ of all people aged 65 years and over in the Netherlands. This number is expected to rise to 1160000 in 2030. It is estimated that $38 \%$ of people older than 75 are frail. With this increase, the number of people with physical, psychological and/ or social problems will also increase. ${ }^{10}$

\section{Community dwelling older adults}

This increase in community dwelling older adults is not just the case in the Netherlands. Globally, $40 \%$ of the older adults (aged 60 years or over) are community dwelling, and they live alone or only with their spouse. ${ }^{5}$ Community dwelling older adults are far more common in developed countries; about $75 \%$ of older adults live independently here, compared with only $25 \%$ in developing countries and $12.5 \%$ in the least developed countries. As countries develop and their populations continue to age, community dwelling older adults will most likely become much more common in the future. ${ }^{5}$

\section{Changes in the Dutch long-term care}

The policy of the Dutch government is focused on enhancing self-sufficiency and on living independently as long as possible. ${ }^{2}$ People are expected to be more independent and self-reliant. ${ }^{14}$ This means that in the years to come, more and more people with long-term complex problems will have to live independently. Since January 2015, institutionalisation in the Netherlands is only possible for people who need intensive care and supervision day and night. The long-term care Act (Wlz, Dutch acronym) comprises rules regarding long-term care and will replace the Exceptional Medical Expenses Act (AWBZ). Since January 2015, the responsibility for support and welfare delivered at home is transferred to the Social Support Act (Wmo, Dutch acronym), which is executed by municipalities. ${ }^{2}$ Medical care was, and still is, comprised within the Dutch Health Insurance Act (Zvw, Dutch acronym). Private health insurance companies are obliged to offer a core universal insurance package for healthcare at a fixed price for all, whether young or old, healthy or sick. Everyone over 18 pays a flat-rate premium for the standard insurance package. ${ }^{15}$

\section{Suboptimal care}

There are not many published reports evaluating ties within various types of network organisations in healthcare. ${ }^{3}$ Older adults often receive complex and fragmented care; this may be influenced by their multiple problems in multiple areas of health. ${ }^{16-18}$ Collaborating organisations within a network often have different goals, funding streams and stakeholders, meaning that integration is not easily achieved in practice. ${ }^{6}$ Research has shown that some of the causes of suboptimal care, incidents and care-related harm to patients are a lack of communication, information transfer and cooperation between care providers, formal and informal, within care networks. ${ }^{19-21}$ The absence of one integrated (electronic) system for information transfer may contribute to this problem. ${ }^{22}{ }^{23}$ Uncertainties about responsibilities, when care is provided by multiple care providers, may contribute to fragmented and uncoordinated care. ${ }^{16-18}$ Having multiple different healthcare providers and insufficient information transfer are both classified as specific risk-indicators within the long-term elderly care. $^{24}$ 


\section{Supervision}

In the Netherlands, a social insurance healthcare system exists and supervision on the quality of healthcare is secured internally by quality systems and externally by the IGZ. The IGZ is an independent agency within the Ministry of Health, Welfare and Sport (VWS). The IGZ guards the quality and safety of care using scientific guidelines, field standards and enforcing 29 laws, for example, the Care Institutions Quality Act. ${ }^{25}$ In each care sector, the IGZ collaborates with healthcare providers, insurers and representative groups of patients in order to produce appropriate indicator sets at which the IGZ can supervise. These 'quality indicators' also provide information for patients and they enable healthcare providers to benefit from a good rating, or to improve the quality of their services. Health insurers can use the indicators to support their purchasing and contracting decisions. The IGZ supervises care offered from the Zvw and the Wlz, but is not able to supervise support offered from the Wmo. ${ }^{2}$ When clients have to deal with care delivered from multiple domains, integration of care is essential. This is embedded in the Zvw and in the Wmo. ${ }^{14}$ The changes in the Dutch healthcare system, the expanding population of community dwelling older adults and their use of care at home complicate the supervision for the IGZ, because care for the older adults partially will lie within the responsibility of the municipalities. Also, informal care is not included in IGZ regulation, which means that the IGZ is not able to regulate the total network.

Supervisors are expected to make more active use of patients as sources of information because they potentially provide relevant signals about the quality of care. ${ }^{26}$ The opportunity for patients to be more active has become an important aspect of what is defined as good quality healthcare since the introduction of the Zvw in 2006, where the market-based model entered the Dutch healthcare system. ${ }^{27}$ In this study, the perspective of the patient in relation to supervision is an important aspect.

\section{Basis of this study}

Research on the effectiveness of supervision is increasing; it focuses generally on risk supervision regimes ${ }^{28-30}$ and the effects of enforcement and surveyor styles. ${ }^{31-36}$ Studies on the quality of supervision instruments and decision-making in supervision are limited.

In the Netherlands, multiple initiatives have been undertaken in recent years to start up research concerning this subject. One of these is the foundation of the 'academic collaborative centre on supervision' (AWT, Dutch acronym) in 2011. Here, four different research institutions work together with the IGZ during a 4-year period in order to develop evidence-based supervision. This study is positioned within the AWT, and is executed by the EMGO+Institute/VU University Medical Centre in close collaboration with the IGZ, in order to link research and practice. ${ }^{i}$

\section{Objective and research questions}

To summarise, one unified definition of frailty is still lacking and research evaluating ties among organisations, care professionals and informal care providers in various types of networks in healthcare is scarce. ${ }^{3}$ Also, it is unclear how care networks around community dwelling frail older adults are formed and to what extent collaboration and coordination are present. The Dutch healthcare system is currently in transition and the IGZ has to respond to effects of this transition. Independence and self-reliance are important topics for frail older adults and their social network. The patient should be the focal point of care and not systems or organisations around them. The current supervision frameworks of the IGZ are focused on individual care providers and organisations and therefore do not meet all of these criteria. Supervision from the patient's perspective should be explored.

The participants in this study will be community dwelling frail older adults, aged 75 years and older, since dependency of care rises exponentially after the age of 75 , and their care providers. ${ }^{37}$ The objectives of this study are to provide insight on risks for community dwelling older adults and to develop and evaluate a newly developed framework for the supervision of care networks by the IGZ for community dwelling frail older adults.

This new form of supervision may contribute to the improvement of different existing problems involving the lack of communication, information transfer and cooperation in care. This newly developed framework may function as a basis for supervision of other complex care groups. With this study, an answer to the following research questions will be sought.

\section{Research questions}

1. What risks for community dwelling older adults are most urgent from different perspectives?

2. To what extent is it possible to develop quality indicators for continuity of care within care networks which make it possible for the supervisor to identify a quality or safety problem at an early stage?

3. How is coordination and responsibility of care for the community dwelling older adults in a care network arranged by the care organisations and professionals?

${ }^{i}$ iBMG, Erasmus University, Rotterdam, Nivel Utrecht, EMGO+ Institute/VU University Medical Centre, IQ healthcare, Radboud University, Nijmegen are the four involved research institutions. The AWT has the following aims:

- Professionalise supervision by the evaluation of current practices and by conducting effect studies

- Contribute to the development of supervision methods and instruments

- Extend and spread the scientific knowledge about supervision Within the AWT, the link between practice, research and education is the most important feature. Questions for research arise from daily practice in supervision. 
4. To what extent is it possible for the IGZ to use the experiences of clients in supervision to identify and test the quality of care networks?

5. What possible influences of the newly developed supervision framework for care networks for frail community dwelling older adults can be detected?

\section{METHODS AND ANALYSIS}

Study design

The total study has a mixed methods approach and it consists of four phases. Owing to the planning of these phases, the results from a previous phase provide the necessary input for the next phase. The total time period planned for this study is 42 months; the study started in January 2013 and is ongoing. A flow chart of the total study and its phases is available in figure 1 . The methods that will be used for each phase are mentioned below. An important aspect of this study is to provide insight from the patient's perspective.

\section{Setting and study population}

This study focuses on community dwelling older adults, aged 75 years and older, who live independently and are expected to be frail. The care networks of frail older adults may consist of a medical specialist, a general practitioner, homecare, social care, psychological care, a pharmacist, physiotherapist or occupational therapist, family, friends, neighbours, welfare, volunteers and others. The older adults will be approached through different organisations in two different regions in the Netherlands. These organisations are involved in the care or welfare of these older adults, like service flats, homecare, general practitioners, housing cooperatives, and welfare and volunteer organisations. They are acquainted with these older adults and are therefore able to find the right population to participate in this study. These organisations are asked to find participants aged 75 years and older who are frail, based on the knowledge of representatives of that organisation.

Frailty will be operationalised by using the Tilburg Frailty Indicator (TFI), which is based on the conceptual model of frailty by Gobbens et al. ${ }^{9}$ It consists of 15 questions covering different domains: physical, social and psychological frailty.

\section{Phase I risk analysis}

In the first phase of this study, a so-called scoping review will be conducted. The purpose of this scoping review is to explore the existing literature covering risks for community dwelling frail older adults because of the diversity in this field. The rationale behind this review is for the researcher to get acquainted with the existing literature on risks and frail older adults and to eventually compare this with risks mentioned by the older adults and their care providers. The scoping review will be conducted by one researcher using the relevant criteria of the PRISMA-P checklist. The intended information sources are PubMed as the electronic database for scientific literature, reports written by the IGZ and other stakeholders, expert interviews and policy documents of the Dutch government. At least the following search terms will be used in the search strategy for the electronic database to collect relevant literature: Risk, Adult-frail older $(\mathrm{MeSH})$, Aged (MeSH), Patient safety (MeSH), Medicalisation (MeSH), Community Networks (MeSH), Continuity of care, Primary care, Fragmented care, Delivery of Health Care-integrated (MeSH), Community dwelling, Care coordination and Information transfer.

All the literature written in English or Dutch will be eligible for this review. After reading the title and summary, the researcher will decide whether the total article or report is relevant and will decide on its inclusion or exclusion. The quality of the studies will not be systematically assessed. Author(s), journal, year and a summary of methods and results, including the identified risks, will be extracted from each included source and registered into an Excel worksheet after inclusion.

All risks or risk factors mentioned in the literature will be analysed and the researcher will categorise and map them. During this last step, a second researcher is involved to discuss the categorisation of the different risks.

\section{Phase II pilot study}

In this phase, a qualitative pilot study will be conducted. Semistructured interviews with different organisations and community dwelling older adults will be held, as well as structured interviews with their care providers. To get insight into risks concerning community dwelling older adults, information about the composition of their care network, satisfaction about the delivered care and collaboration within the care network will be collected. Approximately 25 frail older adults will be approached via different organisations $(n=5)$; the total number of community dwelling older adults will depend on the moment when saturation of the data is reached. First, two researchers will interview a representative of the organisation to collect information about their policies and perceived risks regarding community dwelling frail older adults. The organisation will select older adults of 75 years who are able to give their consent and seem frail to the representatives. The organisation will approach them for participation. They will hand them informed consent forms. After receiving the informed consent from the frail older adults, one researcher will approach them by phone to confirm a date and time for the interview at their home, which will be conducted by the same researcher and recorded on tape. Structured questions will be analysed per question and open-ended questions will be analysed and coded using Atlas.ti V.7 (ATLAS.ti Scientific Software Development Company, GmbH, Berlin, Germany). To reach consensus about the coding, peer debriefing will be used. The interviewer will map the care network of the participant and ask them about their satisfaction with the care they receive 
Flowchart: Supervision of care networks for frail community dwelling older adults of 75 years and older

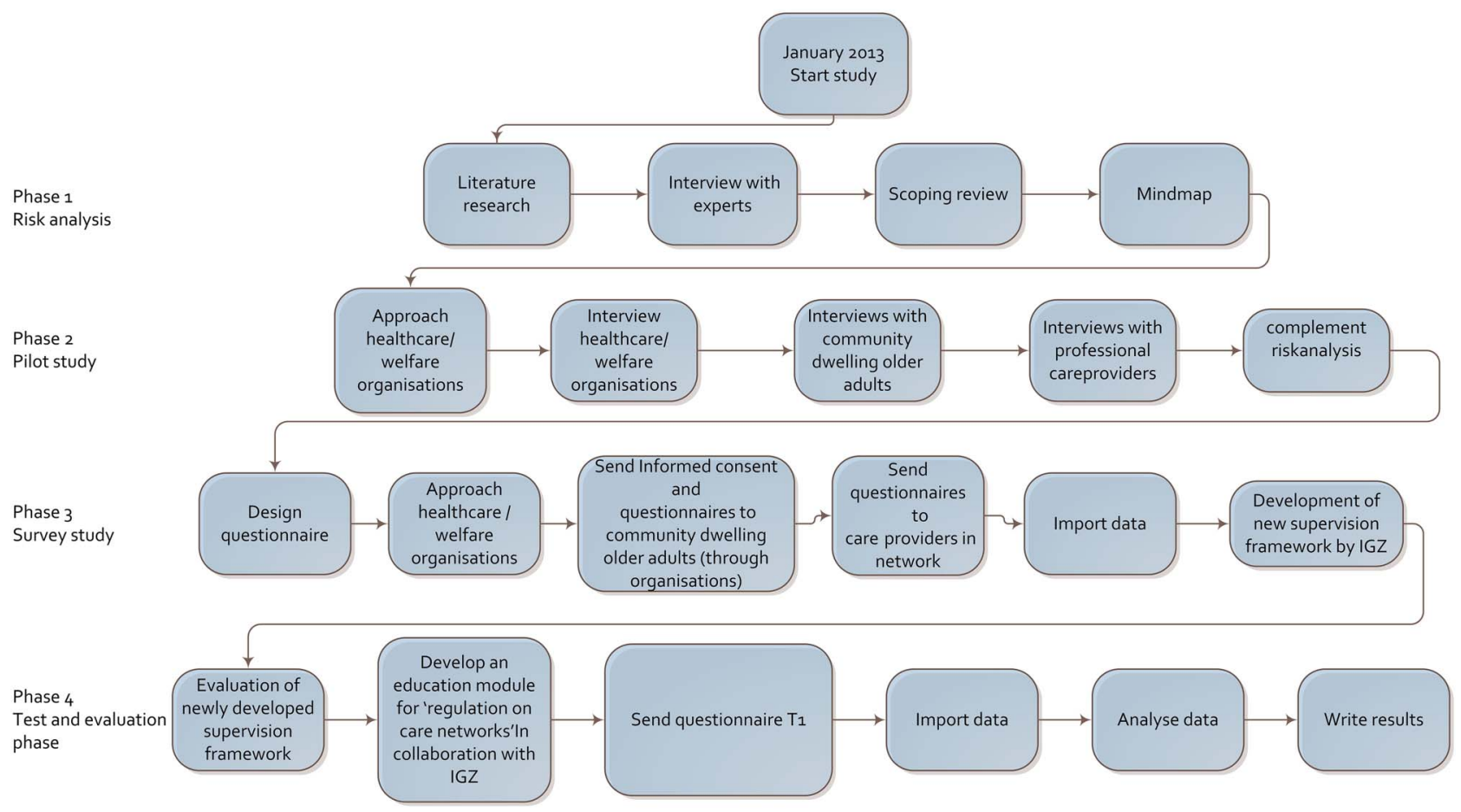

Figure 1 Flow chart: supervision of care networks for frail community dwelling older adults aged 75 years and older.

and about perceived risks. The $\mathrm{TFI}^{9}$ will be used to assess frailty. The needs and wishes in care of the frail older adult are a central theme during this interview. In addition, the researcher will ask the frail older adult written permission to interview their care providers by phone in order to ask them questions about collaboration, coordination and direction of their care $(n=25)$.

During phase II, input for the development of questionnaires for phase III will be gathered. The risks mentioned most often by the older adults, their care providers and the organisation will be used in the questionnaire in order to categorise these risks by importance. Phase II should also point out whether approaching the frail older adults through organisations is a productive way.

\section{Phase III survey}

The aim of this phase is to collect information on the composition, collaboration and coordination of care networks in two different regions in the Netherlands and to prioritise the risks mentioned during phase II. The two involved researchers will compose two questionnaires using the results from phase II, one for the older adults and one for their care providers. The survey study will be carried out by the same researcher who conducted the interview. The questionnaire for the older adults will cover at least the following themes: social demographic characteristics, risks for community dwelling older adults, wishes and needs in care and welfare, involved care providers (formal and informal) and frailty. At least 200 frail older adults will be approached through organisations in order to fill in the questionnaire. The intention of these questionnaires is to provide insight on health and care networks of community dwelling older adults in the province of North-Holland in the Netherlands. After receiving permission from the older adults, all of their mentioned care providers are asked to fill in a questionnaire as well. This questionnaire will cover the following subjects: involved care providers for the older adult, collaboration and coordination with other care providers, signaling and frailty of the older adult. The questionnaires will function as a baseline measurement. The questionnaires will be analysed using descriptive statistics using Statistical Package for Social Science (SPSS Inc, Chicago, Illinois, USA).

\section{Phase IV evaluation}

A project team consisting of approximately eight employees of the IGZ will start the development of a supervision framework during phase IV, for which the results from the previous phases of this study will provide input. The older adults' perspective is prominently included in this supervision framework. This new framework will include riskbased supervision. The risks identified in phases I and II of the study will be considered by the IGZ for the development of the framework. The newly developed supervision framework will be tested during three different pilots by the IGZ. The researchers will closely follow these pilots, 
and one researcher will evaluate them by interviewing community dwelling older adults who are involved in the pilots of the IGZ $(n=12)$. Depending on the preferences of the older adults, the semistructured interviews will be face to face or by phone. The topics of these interviews will at least cover: background and frailty, reasons to participate, the appreciation of their involvement in the supervision method and satisfaction about the contact moments. Both researchers will organise and conduct focus group meetings with care providers and inspectors, which will take place separately. The focus group meetings will be held with approximately 6 to 10 participants. The methodology for qualitative interviewing and organising focus groups described by Evers ${ }^{38}$ will be used. Topics discussed in the focus groups will be: bottlenecks using the framework, possible gaps in the framework, adequacy of information in the framework, correct target group, possible changes and possible enhancements.

Next to the pilots in phase IV, the second measurement of the questionnaire will take place among the participants of phase III after 1 year. This questionnaire will give insight into changes in perceived risks for community dwelling older adults during the healthcare transition in the Netherlands. Care providers will also be asked about their experiences during the transition. There is a high risk of dropouts in this population because of age and frailty; this is an important aspect which will be taken into account by the researchers. Results will be translated into practice by developing an educational module on network supervision for future inspectors in close collaboration with the IGZ.

\section{Data collection}

Phases I and II both include qualitative methods; data in these phases will be gathered with interviews. Information from phases III and IV will be gathered using interviews, focus group meetings, questionnaires and document analysis.

\section{Outcome measures}

First, this study aims to give insight on the possible risks for community dwelling frail older adults, the manner in which direction and coordination are arranged in a care network, the possibilities to develop indicators, and whether the experiences of clients are usable for supervision. Also, the possible consequences of the Dutch healthcare transition in the care for the community dwelling older adults are examined. This is mainly an exploratory study.

The outcomes of interest in this study are as follows:

- In what way responsibility and direction are organised in the network of the client and what role the client has.

- The percentage of care providers that is aware of the involvement of other care providers within a network

- The percentage of care providers that has arrangements about collaboration
- Competences and skills of the care providers in the network

- In what way attention for the competences of the client and of the informal care providers is guaranteed

- Whether risks concerning the safety of a client are discussed

Second, the newly developed supervision framework will be evaluated using structure and process indicators which will be developed during phase IV; these structure and process indicators will function as secondary outcome measures. Other secondary outcome measures include frailty, needs and wishes, satisfaction with care and multimorbidity of the older adults. These outcomes are assessed during interviews and by questionnaires for the older adults.

\section{Data analysis}

Important themes discussed during the interviews will be identified. The interviews will be summarised per question and open-ended questions will be coded and analysed using Atlas.ti V.7 (ATLAS.ti Scientific Software Development Company, GmbH, Berlin, Germany). The interviewer will analyse the qualitative data, which minimises the chance of misunderstanding the data. Peer debriefing by the other involved researcher will then be used to reach consensus about coding. Statistical Package for Social Science (SPSS Inc, Chicago, Illinois, USA) will be used to analyse quantitative data of the study gathered by the questionnaires over time. Frequencies and descriptive statistics will be used to explore the quantitative data and will be conducted by one researcher.

\section{Ethics and dissemination}

Informed consent and ethical approval

This study is funded by The Netherlands Organisation for Health Research and Development (Dutch acronym: ZonMw). The study is approved by the Scientific Committee of the EMGO+institute and the Medical Ethical review committee of the VU University Medical Centre. The participants in this study have to sign an informed consent form before inclusion can take place. All information gathered about the participants will only be used for this study and is processed separately from participant identifiers. The hard copy data will be stored in a secured locker, which can only be accessed by the involved researchers. The digital information will be processed by code. A number will be allocated to each participant; the key to this number will only be accessible to the involved researchers and saved in a secured file.

\section{Dissemination plan}

The complete study should at least deliver the following results: a risk analysis with risk indicators for care networks of frail community dwelling older adults, an evaluation of a new supervision framework, an educational module for 'supervision on care networks', a report of 
the total study and multiple scientific articles with the proposed subjects:

- Risks for community dwelling older adults

- Inventory of care networks

- Evaluation of a newly developed supervision framework

\section{Feasibility}

A steering committee is composed where delegates of different stakeholders will discuss the progress of this study. This committee will be informed about the progress and results of the study periodically, and they will meet twice a year. Their involvement should enhance the feasibility and applicability of the research.

Owing to the close collaboration with the IGZ during all phases of the study, the feasibility within the IGZ is expected to be achievable.

The feasibility mostly depends on the cooperation of participants, (care) organisations and care professionals. Since this study is performed in cooperation with the IGZ, it may enhance participation of different people and organisations, or it may scare them off. There also has to be attention for possible 'window dressing' of care providers. The current care situation and changes in this situation should be surveyed as objectively as possible. Owing to the independent position of the researchers, it is their task to monitor and guard these issues.

\section{Relevance}

Community dwelling frail older adults are a rising population in different developed countries. They have to, and mostly want to, live independently as long as possible, but they may experience multiple health problems. Different care providers from different domains should form a collaborating care network around these community dwelling frail older adults. However, current laws, field standards and frameworks offer too little for the IGZ to supervise care networks for community dwelling older adults in the current situation. Some standards exist, but they are not widely accepted.

As discussed above, the transition of the Dutch healthcare system is another factor to take into account for supervision by the IGZ. More tasks and responsibility concerning care and welfare for the community dwelling older adults fall under the municipalities since January 2015. It is yet unclear how supervision should be formed around these changes, because the IGZ is not legally able to regulate the municipalities and types of informal care. Also, independence and self-reliance for the community dwelling older adults are important topics during this transition. ${ }^{2} 14$ Current supervision frameworks are focused on organisations and individual care providers, but not on networks. This means that the IGZ has to develop a new supervision framework in order to react to the changes in the Dutch healthcare system. The municipalities and health insurers have the assignment of making sure that a continuum is created for support, care and cure. ${ }^{14}$ It should be adjusted and integrated in such a way that the client is not burdened. This could be a starting point for the IGZ in order to regulate the collaboration and coordination within a care network. Supervision on the integrated quality and safety of longterm care for the older adults should also focus on the alignment of the different components. At the regional level, explicit norms should be set by the involved professionals. When responsibility is better anchored, the IGZ should better be able to supervise set norms.

Owing to the rising number of frail older adults, the Dutch healthcare transition and therefore a rising number of community dwelling older adults, it is important to better understand how the IGZ is able to regulate care networks. This study will map all possible risks within the care for frail older adults, survey the composition of different networks, assist the IGZ in the development of a new supervision framework and evaluate it in networks concerning frail older adults aged 75 years and older in the Netherlands.

Contributors DV has written the manuscript and will collect the data. HM is involved in execution of the study and has critically reviewed this manuscript. PR was involved in critically reviewing this manuscript for important intellectual content. CW obtained research funding, was involved in the design of the study and critically reviewed the manuscript for important intellectual content. All authors read and approved the final manuscript.

Funding This work was supported by The Netherlands Organisation for Health Research and Development (ZonMw) (grant number 80-83505-98-004).

Competing interests None declared.

Ethics approval The Medical Ethical review committee of the VU University Medical Centre.

Provenance and peer review Not commissioned; peer reviewed for ethical and funding approval prior to submission.

Open Access This is an Open Access article distributed in accordance with the Creative Commons Attribution Non Commercial (CC BY-NC 4.0) license, which permits others to distribute, remix, adapt, build upon this work noncommercially, and license their derivative works on different terms, provided the original work is properly cited and the use is non-commercial. See: http:// creativecommons.org/licenses/by-nc/4.0/

\section{REFERENCES}

1. Gulmans J, Vollenbroek-Hutten MM, Van Gemert-Pijnen JE, et al. Evaluating quality of patient care communication in integrated care settings: a mixed method approach. Int J Qual Health Care 2007;19:281-8.

2. Dutch House of Representatives, Parliamentary papers II 20132014, 30597, no. 280, november 3, 2014. p.1. The Hague.

3. Minkman MM, Ahaus KT, Huijsman R. A four phase development model for integrated care services in the Netherlands. BMC Health Serv Res 2009;4:42.

4. Van Wijngaarden JD, de Bont A, Huijsman R. Learning to cross boundaries: the integration of a health network to deliver seamless care. Health Policy 2006;79:203-13.

5. United Nations. Department of economic and social affairs, population division. New York: World Population Ageing 2013 ST/ ESA/SER.A/348, 2013.

6. Buchner DM, Wagner EH. Preventing frail health. Clin Geriatr Med 1992;8:1-17.

7. Sternberg SA, Wershof Schwartz A, Karunananthan S, et al. The identification of frailty: a systematic literature review. J Am Geriatr Soc 2011;59:2129-38.

8. De Vries NM, Staal JB, van Ravensberg CD, et al. Outcome instruments to measure frailty: a systematic review. Ageing Res Rev 2011;10:104-14.

9. Gobbens RJ, van Assen MA, Luijkx KG, et al. The Tilburg Frailty indicator: psychometric properties. J Am Med Dir Assoc 2010;11:344-55. 
10. Van Campen C. Frail older adults [Original title in Dutch: Kwetsbare Ouderen]. Dutch Institute for Social Research (SCP) 2011-10 The Hague, Netherlands: SCP.

11. Chi-tat Leung A, Chi-pun Liu, Wing-sun Chow N, et al. Cost-benefit analysis of a case management project for the community-dwelling frail elderly in Hong Kong. $J$ Appl Gerontol 2004;23:70-85.

12. Niskanen J. Finnish integrated care? Int J Integr Care 2002;2:1-10.

13. Leichsenring K. Developing integrated health and social care services for older persons in Europe. Int J Integr Care 2004;4:e10.

14. Dutch House of Representatives, Parliamentary papers II 20122013, 30597, no. 296, April 25, 2013. p.2. The Hague.

15. Healthcare insurance [original title in Dutch: Zorgverzekering] [http:// www.rijksoverheid.nl/onderwerpen/zorgverzekering]

16. Callahan EH, Thomas DC, Goldhirsch SL, et al. Geriatric hospital medicine. Med Clin North Am 2002;86:707-29.

17. Black $D$, Bowman $C$. Community institutional care for frail elderly people. BMJ 1997;315:441-2.

18. Kodner D. The future of long-term care: Results and implications of a Delphi study. PhD Thesis, The Union Institute \& University, 1992.

19. Joeloemsingh S. Clear agreements- Division of responsibilities as condition to deliver accountable care [Original title in Dutch: heldere afspraken - verantwoordelijkheidstoedeling voorwaarde voor verantwoorde zorg]. Med Contact (Bussum) 2007;62:204-6.

20. Dwyer K. Flawed communication systems result in patient harm. Int J Qual Health Care 2002;14:77.

21. Keyes C. Communication gaps in paediatric care. Int J Qual Health Care 1999;11:533-4.

22. van den Berg WAM, Helfrich E, Colen HBB, et al. An instrument that enhances medication safety [original title in Dutch: Een instrument dat de medicatieveiligheid vergroot]. Farmaceutisch Weekblad 2002;137:1544-7.

23. de Blok $\mathrm{C}$, Vat $\mathrm{L}$, van Soest-Poortvliet $\mathrm{M}$, et al. Research concerning information transfer between hospital and long term care [Original title in dutch: onderzoek naar de overdracht van patiëntinformatie tussen ziekenhuizen en VVT]. Utrecht: Nivel, 2012.

24. van den Brink-Muinen A, Wagner C. Risk-indicators for long term care [Original title in Dutch: Risico-indicatoren voor de langdurige zorgverlening]. Utrecht: Nivel, 2004.
25. IGZ, VWS. Enforcement framework of the inspectorate [Original title in dutch: IGZ-handhavingskader. Richtlijn voor transparante handhaving]. The Hague: Healthcare inspectorate, 2008, revised 2013.

26. Rothgang $\mathrm{H}$, Cacace $\mathrm{M}$, Grimmeisen $\mathrm{S}$, et al. The changing role of the state in healthcare systems. Eur Rev 2005;13:187-212.

27. Adams SA, van de Bovenkamp HM, Robben PBM. Including citizens in institutional reviews: expectations and experiences from the Dutch Healthcare Inspectorate. Health Expect 2013. doi:10.1111/hex.12126

28. Enthoven AC, van de Ven WP. Going Dutch-managed-competition health insurance in the Netherlands. N Engl J Med 2007;357:2421-3.

29. Adil M. Risk-based regulatory system and its effective use in health and social care. J R Soc Promot Health 2008;128:196-201.

30. van Dishoeck AM, Oude Wesselink SF, Lingsma, HF, et al. Transparency: can the effect of governmental surveillance be quantified? [Original title in Dutch: Ttransparantie: is het effect van toezicht te meten? ]. Ned Tijdschr Geneeskd 2013;157:A1676.

31. Hood C, Rothstein H, Baldwin R. The government of risk. Understanding risk regulation regimes. Oxford, New York: Oxford University Press, 2001.

32. Greenfield D, Braithwaite J, Pawsey M. Healthcare accreditation surveyor styles typology. Int J Health Care Qual Assur 2008;21:435-43.

33. Day $\mathrm{P}$, Klein $\mathrm{R}$. The regulation of nursing homes. Milbank $Q$ 1987:65:303-47.

34. Hutter BM. Variations in regulatory enforcement styles. J Law Policy 1989;2:153-74.

35. Braithwaite J, Makkai T, Braithwaite V. Regulating aged care. Ritualism and the new pyramid. Cheltenham, UK: Edward Elgar Publishing limited, 2007.

36. Mascini P, van Wijk, E. Responsive regulation at the Dutch Food and Consumer Product Safety Authority: an empirical assessment of assumptions underlying the theory. Regul Governance 2008;3:27-47.

37. de Boer A. Changes in the lives and living situation of elderly persons in the Netherlands. The Hague: SCP, 2006.

38. Evers J. Qualitative interviews: art and skill [original title in Dutch]. The Hague: Boom Lemma uitgevers, 2013:97-136 